into seasons, but which is usually ignored in commercial and educational practise. The quarters as grouped in the scheme proposed are those that are most recognized in the current time divisions of the business, social and educational worlds. There are indeed climatic reasons for our seasonal grouping in disregard of the year division, but, after all, March is only slightly less wintry than December, and June scarcely more summery than September. A strict seasonal adjustment is embarrassed by the lag of the climatic effects behind their astronomic causes and by the opposite phases which the seasons assume in the northern and southern hemispheres. In the tropics the influence of conditions other than the sun's position on the nature of the seasons adds to the difficulty. To this is added also the lack of strict adjustment of either the present or the proposed calendar to the astronomical divisions initiated by the equinoxes and solstices. Even if a strict adjustment of the calendar to these were made, the climatic effects would lag behind the astronomical divisions in a vague and fluctuating way. Under the proposed scheme, each seasonal quarter would start about ten days after the astronomic event that may be said to initiate it. This may be construed as some recognition of the lag of climatic effect, though it is merely accepting current usage in starting the new year.

With the shifting of the months as proposed, and accepting the ten-day delay as a compromise lag, each quarter would mark a climatic movement of a single kind, a phase of increase of insolation or a phase of decrease of insolation; the winter, a movement from the lowest insolation in the northern hemisphere to medium insolation (the opposite, of course, in the southern hemisphere); the spring, a movement from medium insolation to the highest insolation; the summer and the fall, the corresponding phases of decrease. While as systematists and as scientists we might prefer a shift from present usage to the exact dates of the solstices and equinoxes, it would probably be asking too much of the inertia of mankind to change the calendar so as to effect this. Besides, these astronomical divisions are not strictly equal, and that would give us trouble.

In the matter of holidays, the scheme seems to lend itself fairly well to current practise and is perhaps well suited to mold future practise as well. The 28th day of December would always fall on Sunday and be the immediate fore-runner of Christmas. Christmas itself would always fall on the Monday of Christmas week. Our greatest holiday would thus have a distinctive place of its own at the head of its special week, instead of falling in the midst of a month and on a constantly shifting day of the week. The winter holiday season would be closed usually by New Year's Day, but on every fourth year by Leap Day, following New Year's Day. The Christmas holidays would thus be lengthened to nine days or to ten days.

Easter week would always begin on Monday, the 85th day of the year, and the days of the week might have the special designations, Easter Tuesday, Easter Wednesday, and so on, ending with Easter Sunday, which would appropriately be followed by the spring season.

The Julian week would embrace our national holiday, which would always be Julian Thursday. The Julian week might well come to embrace the observances that mark the end of the educational year.

The Gregorian week would fall at a time well suited to the harvest festivials, the fairs, etc.

The close weeks between each of the threemonth groups would form a natural time for closing books for the quarter, rounding up accounts, making out quarterly reports, holding official corporation meetings, declaring dividends, etc., in the world of affairs, and for vacations and rest intervals in the educational and professional worlds.

The authors of the rectifications that gave us our present calendar are recognized in the naming of the Julian and Gregorian weeks.

\section{T. C. Chamberlin}

\section{ANTARCTICA AS A FORMER LAND CONNECTION} BETWEEN THE SOUTHERN CONTINENTS

LEST my position with reference to this subject be misunderstood, I wish to state that my 
letter entitled "Shackleton's Contribution to Biogeography" was intended as suggestive rather than positive. Such may be gathered from the opening paragraph. But perhaps some may conclude from it that I view Antarctica as practically the only land connection that has existed between the various continental masses, or between the eastern and western hemispheres; that I consider that faunal and floral elements have ever traveled northward, and have reached the northern continents through the southern from Antarctica as a center of dispersal. This is not the idea that I wish to convey. There have been northward and southward dispersals of types, and eastward and westward dispersals as well. There has certainly been land connection between Eurasia and North America in the Bering region in times past, and many types have passed over that bridge, some going one way and some the other. There are distinctively northern types that have spread southward into the continents of the southern hemisphere, but there are also southern types that have spread northward. There is evidence for believing that the southward dispersals are much more recent than the northward, taken as a whole.

The biogeographical rôle which I conceive Antarctica to have played is that of a center of distribution of the earlier forms of life; and later, perhaps, an exchange ground between the southern continents for old-type stocks, many or some of which traveled northward into the continents of the northern hemisphere. The main point after establishing the Antarctic contacts is to determine the length of their duration with the southern continents. It is quite possible that none of these contacts persisted into Tertiary time, and my suggestion that Africa may have been connected with the southern mass until the Miocene is perhaps wide of the mark. The distribution of certain forms which prompted the suggestion may have to be otherwise explained. It was during Paleozoic and Mesozoic times that I consider Antarctica to have been especially active as a center of dispersal and exchange. I should better have said in my former com- munication that during Mesozoic (Jurassic to Cretaceous) times the continent was probably not dissimilar to present-day South America and Asia in average elevation; and that its subsequent further uplifting, together with the enormous weight at times of its ice-sheet, which has repeatedly extended and decreased in accordance with changing conditions of altitude and temperature, caused its shelf lines to sink beneath the ocean. Its complete isolation may have been effected before the Tertiary. On the other hand, some of its contacts may have prevailed until the Oligocene. At all events there seems evidence enough to indicate that at one time it played an important part in the dispersal of old-type forms. Doubtless Antarctica is the most remotely ancient of the continents, as indicated by its greatest average elevation.

I am well aware that most European and North American students consider the great majority of distinctively Tertiary and later types to have originated in the northern hemisphere, and I may add that this is also my opinion. But it is well known that, at the beginning of the Tertiary, many types of the higher insects were already in existence, some of which have persisted with little change to the present day. This must necessarily have been the case, since we find their remains scattered through Eocene, Oligocene and Miocene deposits. While evolution has undoubtedly been most active in the development of new types in the northern hemisphere since early Tertiary time, and the prevailing trend of migration has consequently been to the southward, there seems much evidence to indicate that prior to that time the reverse was the case in large part at least.

I shall be glad to see an expression of views on this subject from paleontologists who have made especial studies of various phyla.

\section{Charles H. T. Townsend}

Piura, Peru, September 27, 1910

\section{AMERICAN EDUCATION}

To the Editor of Science: The criticisms passed on American education by Mr. Gunn 